This document is the accepted manuscript version of the following article:

Maluk, C., Bisby, L., \& Terrasi, G. P. (2017). Effects of polypropylene fibre type and dose on the propensity for heat-induced concrete spalling. Engineering

Structures, 141, 584-595. https://doi.org/10.1016/j.engstruct.2017.03.058

\title{
1 Effects of Polypropylene Fibre Type and Dose on the Propensity for 2 Heat-Induced Concrete Spalling
}

3 Cristian Maluk ${ }^{1, *}$, Luke Bisby ${ }^{1}$, and Giovanni P Terrasi ${ }^{2}$

$4 \quad{ }^{1}$ School of Engineering, The University of Edinburgh, UK

$5 \quad{ }^{2}$ Empa, Swiss Federal Laboratories for Material Science and Technology, Switzerland

\section{Abstract}

7 The term high-performance concrete (HPC) is typically used to describe concrete mixes with 8 high workability, strength, and/or durability. While HPC outperforms normal strength 9 concrete in nearly all performance criteria, it also displays a higher propensity for heat10 induced concrete spalling when exposed to severe heating or fire. Such spalling presents a 11 serious concern in the context of the historical approach to fire safe design of concrete 12 structures, where structural engineers typically rely on concrete's inherent fire safety 13 characteristics (e.g. non-combustibility, non-flammability, high thermal inertia). It has been 14 widely shown that the inclusion of polypropylene (PP) fibres in concrete mixes reduces the 15 propensity for heat-induced concrete spalling, although considerable disagreement exists 16 around the mechanisms behind the fibres' effectiveness. This paper presents an experimental 17 study on the effects of PP fibre type and dose on the propensity for heat-induced spalling of 18 concrete. A novel testing method and apparatus, the Heat-Transfer Rate Inducing System (H19 TRIS) is used to test medium-scale concrete specimens under simulated standard fire 20 exposures. Results show (1) that although the dose of PP fibres (mass of PP per $\mathrm{m}^{3}$ of fresh concrete) is currently the sole parameter prescribed by available design guidelines, both the PP fibre cross-section and individual fibre length may have considerable influences on the effectiveness of PP fibres at reducing the propensity for heat-induced concrete spalling; and (2) that current guidance for spalling mitigation with PP fibres is insufficient to prevent spalling for the HPC mixes tested.

\section{Keywords}

27 Heat-induced concrete spalling; high-performance concrete; polypropylene fibres; fire testing; H-TRIS.

\section{"Corresponding Author}

Currently at: School of Civil Engineering, The University of Queensland, Australia

Address: School of Civil Engineering, The University of Queensland, Brisbane QLD 4072, Australia

Email: c.maluk@uq.edu.au

Tel: +61 733653518 


\section{INTRODUCTION \& BACKGROUND}

31 Structural engineers have historically relied on concrete's inherent fire safety characteristics 32 (e.g. non-combustibility, non-flammability, high thermal inertia) for the fire safe design of 33 concrete structures [1]. Modern advances in concrete construction have been driven by the 34 need to build faster and higher, to reduce cost, increase sustainability, and increase service lives. The term high-performance concrete (HPC) describes concrete mixes with high workability, strength, and durability, and low compressive creep [2, 3].

While HPC outperforms normal concrete in nearly all performance criteria, "its Achilles heel is its performance when exposed to fire" [4]; it has a high propensity for explosive spalling under severe heating and also experiences more rapid reductions in compressive strength than 'normal' strength concrete at elevated temperature [5]. Given its ever-increasing use in highrise buildings (particularly for columns), and in tunnel structures and lining segments [6], the heat-induced spalling resistance of HPC is a critical issue for the concrete industry (in-situ and precast).

\subsection{Spalling}

Heat-induced spalling of concrete, which is widely perceived as being a random phenomenon [7], occurs when the exposed surface of heated concrete flakes away in a more or less violent manner (see Figure 1). As a consequence, the concrete cover to the internal reinforcement is reduced, resulting in more rapid temperature increases of the internal reinforcement and within the core of the structural element, in addition to a direct influence on load bearing capacity due to the loss of physical or effective cross sectional area. Heat-induced concrete spalling presents a potentially serious concern in the context of the historical approach to fire safe structural design of concrete structures, where spalling is less common and presumed as 
'implicitly' accounted for in prescriptive, tabulated fire design guidance. The concrete

54 industry is beginning to grapple with the implications of the clearly demonstrated increased

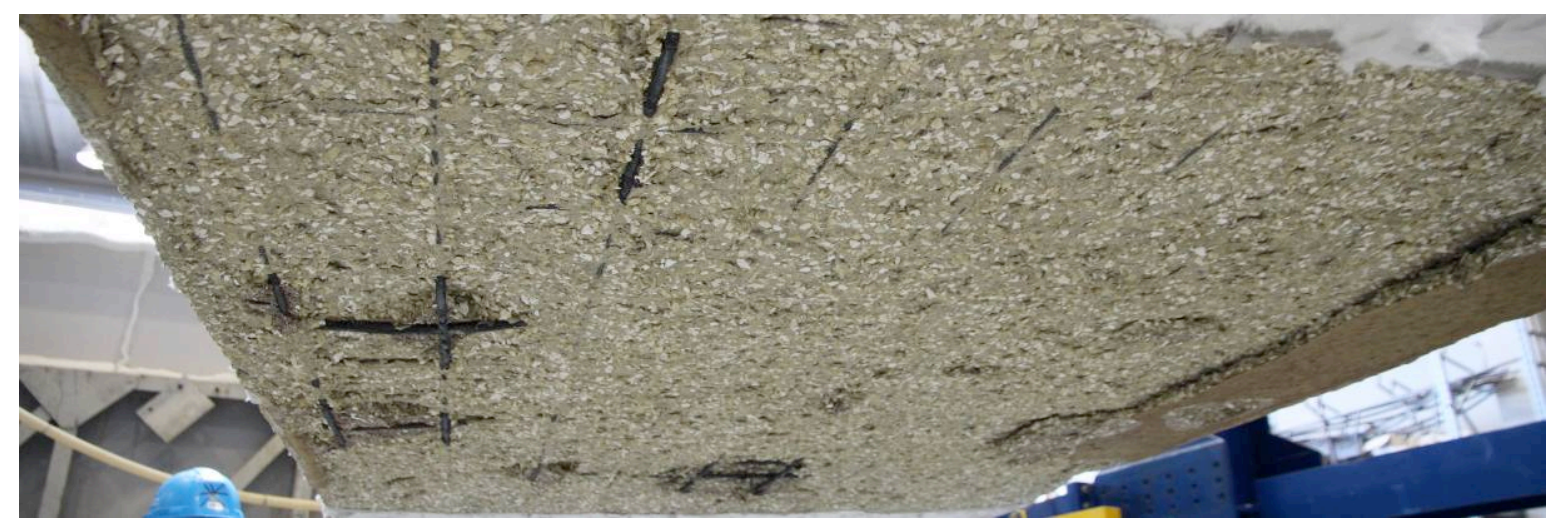

Figure 1 - Evidence of the significant extent of spalling on the soffit of a large-scale concrete specimen after a standard fire resistance test (photo courtesy Ieuan Rickard).

60 Heat-induced concrete spalling is by no means a new phenomenon (e.g. [9] to [18]), although 61 as noted it is increasingly a concern for modern HPC mixes. Numerous past researchers have 62 studied heat-induced concrete spalling, mainly focusing their efforts on:

- understanding the thermo-physical mechanisms leading to spalling, thus studying the

64 factors which influence its occurrence $[11,12,17,18,19]$;

- modelling (analytically or numerically) the occurrence of spalling [20, 21];

- modelling of the potential impacts of spalling on the load bearing capacity of structural

67 systems [22, 23]; and 


\subsection{Polypropylene fibres}

70 More than three decades of experimental studies have convincingly shown that polypropylene (PP) fibres' (see Figure 2) inclusion in fresh concrete can considerably reduce the propensity for heat-induced spalling of concrete (e.g. $[13,17,25])$. Polypropylene fibres are theorised to alter the transient moisture migration and/or evaporation processes within heated concrete, thus reducing the propensity for spalling (particularly when a thermohydraulic spalling mechanism is dominant). While the mechanisms behind PP fibres' effectiveness remain poorly understood, three potential mechanisms are widely quoted involving the PP fibres generating: (1) discontinuous reservoirs, (2) continuous channels, and/or (3) vacated channels [26].

During heating, rapid volumetric changes of the PP fibres may cause micro-cracks within the concrete matrix surrounding the fibres, thus creating discontinuous reservoirs that enhance moisture migration within concrete. Polypropylene fibre inclusion may also promote the formation of discrete reservoirs by inherently increasing air entrainment within the concrete matrix during mixing and casting.

84 Continuous channels may also be formed at the interfaces between the PP fibres and the concrete matrix due to poor interfacial adhesion and/or a relatively more porous transition zone at the interface. This phenomenon, called Pressure-Induced Tangential Space (PITS) theory [26], is postulated as enhancing concrete moisture migration during heating.

Enhanced moisture transport may also be driven by the formation of vacated channels left behind by pyrolized (or melted) PP fibres during heating. This is the most widely quoted mechanism used to describe the effect of PP fibres in heated concrete [26], however there is

91 little direct experimental evidence for it [7]. 
92 Polypropylene fibres used in concrete applications are commercially available in a range of types and sizes. The most common are monofilament, multifilament, and fibrillated (see Figure 2). Monofilament and multifilament fibres are both manufactured through an extrusion process, with nominal diameters in the range of 10-40 microns. Monofilament fibres are manufactured from a single strand of fibre, while multifilament fibres are made from multiple, combined strands. While the diameter of fibrillated fibres is in the range of monofilament and multifilament fibres, these are manufactured in the form of films that are slit in such a way that they can be expanded into an open network [27] (see Figure 2). Fibres of all types can be cut to the desired length, commonly in the range of 3 to $20 \mathrm{~mm}$. More recently, the use of fibres made out of alternative materials (e.g. polyvinyl alcohol, cellulose, nylon, jute) has been considered, although their effectiveness has yet to be convincingly demonstrated [28].

104 Despite decades of research, the relative importance of the mechanisms that explain the effectiveness of PP fibre inclusion in reducing the propensity for heat-induced concrete spalling remains a matter of considerable debate [26]. Regardless of the currently

107 unquantifiable propensity for spalling, current design and construction guidance for spalling 108 prevention (e.g. $[29,30])$ is solely based on prescribing a dose of polypropylene (PP) fibres which is presumed to assure limited spalling in applications with 'relatively high' spalling risk (e.g. high-strength concrete, high in-service moisture content, high in-service

111 compressive stress, rapidly growing fires, etc).

112 For example, European guidance for concrete in fire [29] recommends including at least $2 \mathrm{~kg}$ 113 of monofilament PP fibres per cubic metre concrete for high-strength ( $>55 \mathrm{MPa}$ cube 114 compressive strength), high moisture content ( $>3 \%$ by mass) and/or concrete with high inclusion of silica fume ( $>6 \%$ by mass of cement). Australian design guidance for concrete in 
116 fire [30] states that the addition of $1.2 \mathrm{~kg}$ of $6 \mathrm{~mm}$ long monofilament PP fibres per cubic

117 metre concrete has a "dramatic effect in reducing the level of spalling". These (and other)

118 guidelines are based on available experimental research on heat-induced concrete spalling,

119 and can only be viewed as potential means of reducing, rather than eliminating, the

120 occurrence of spalling. Physical mechanisms aside, it is reasonable to assume that an

121 optimum (or most 'effective') PP fibre type and dose ought to exist to mitigate spalling under

122 a given set of conditions [24, 31], without unduly sacrificing other properties such as

123 workability or strength.

124

127 Within the project presented herein, the occurrence of heat-induced spalling was examined

128 for 11 specific high-performance, self-consolidating concrete (HPSCC) mixes in which PP

129 fibre type, cross-section, length, supplier, and dose were systematically varied (refer to Table

130 1). Constrained by the manufacturing process needs of an industry project partner (an

131 innovative Swiss precast company), the concrete compressive strength and the workability of

132 the fresh concrete (i.e. slump flow) were maintained constant for all mixes. 
133 The effect of pre-compressive stresses acting on the concrete during testing was also

134 examined, since the end use application of the specific HPSCC mixes studied within the

135 scope of this work involves highly optimized prestressed concrete systems [32]; and since

136 spalling is known to be influenced by in-service stress levels and the development of in-depth

137 differential thermal stresses during heating [7]. The aforesaid highly optimized concrete

138 structural systems have traditionally shown to be extremely vulnerable to the occurrence of 139 spalling [32]. Importantly, rather than seeking to unravel and understand the precise thermo-

140 physical mechanisms contributing to spalling, the current study instead aimed to evaluate the

141 propensity for spalling of the concrete mixes tested under highly repeatable thermal and

142 mechanical conditions; simulating the thermal and mechanical conditions experienced by

143 HPC specimens during a standard fire resistance test (or furnace test).

\section{RESEARCH SIGNIFICANCE}

145 Modern HPC mixes demonstrate an increased propensity for heat-induced concrete spalling

$146[7,8]$. Because credibly modelling the occurrence of spalling is not possible at present, due to

147 the complexity of the various mechanisms possibly contributing to spalling, and because of

148 uncertainty around the potential mechanisms behind PP fibres' effectiveness, this paper

149 presents a carefully controlled experimental study on the effectiveness of PP type and dose,

150 using a novel test method to ensure repeatable testing. Moreover, given the considerable

151 expense of performing traditional large-scale fire resistance tests to examine the spalling

152 behaviour of concrete test specimens, the novel test method, a Heat-Transfer Rate Inducing

153 System (H-TRIS), was developed and is used for studying the 'spalling behaviour' of

154 concrete specimens during heating. The novel method permits multiple repeat testing of

155 identical specimens, with outstanding repeatability and at low economic and temporal costs,

156 which has not previously been possible [7]. 


\section{HEAT-TRANSFER RATE INDUCING SYSTEM (H-TRIS)}

158 The novel H-TRIS fire test method was used for studying the propensity for heat-induced spalling of concrete. Rather than taking the traditional approach of controlling the gas

160 temperature inside a fire testing furnace, the H-TRIS test method permits direct and

161 independent control of the thermal boundary condition; it does this by controlling the time-

162 history of incident radiant heat flux, $\dot{q}_{\text {inc }}^{\prime \prime}$, at the exposed surface of a test specimen [33]. H-

163 TRIS (v1.0 of this apparatus was used in the current study) uses a mobile array of propane-

164 fired radiant panels, along with a mechanical linear motion system and a rotary stepper motor

165 (see Figure 3). The linear motion system can be programed to actively control the relative 166 position between the radiant panels and the exposed surface of a test specimen, thus varying 167 incident radiant heat flux at the exposed surface of the test specimen.

168 For the current study, the imposed thermal boundary condition aimed to replicate the in-depth

169 heating conditions experienced by concrete specimens that had previously been measured 170 during large-scale fire resistance tests of similar specimens and concrete mixes [32]. The specified time-history of imposed incident radiant heat flux aimed to give equivalent in-depth temperature distributions within the concrete as measured during the fire resistance tests. Indepth temperature distributions recorded in large-scale specimens during a set of standard fire

174 resistance tests [32], at 10, 20 and $45 \mathrm{~mm}$ from the exposed surface (refer to Figure 4), were used as inputs for an inverse heat conduction model described below.

176 The time-history of net heat flux, $\dot{q}_{n e t}^{\prime \prime}$, needed to simulate the fire resistance tests was 177 determined using an inverse heat conduction model previously developed by the authors [7, 178 33]. A full description of the inverse model is presented elsewhere, however it is noteworthy 179 that, unlike a traditional heat conduction model in which the thermal boundary condition is 180 assumed and used as an input to calculate the in-depth time-dependent temperature 
distributions within a solid, the inverse heat conduction model uses measured in-depth time

182 dependent temperature distributions as inputs to calculate the thermal boundary conditions.

183 The incident radiant heat flux to be imposed with H-TRIS to give a net heat flux equivalent to

184 that experienced during a fire resistance test was calculated considering the heat flux losses,

$185 \dot{q}_{\text {losses }}^{\prime \prime}$, also accounting for the absorptivity, $\alpha_{S}$, at the test specimen's exposed surface (refer

186 to Figure 5), as follows:

187

$\dot{q}_{\text {inc }}^{\prime \prime}=\frac{1}{\alpha_{s}}\left(\dot{q}_{\text {net }}^{\prime \prime}+\dot{q}_{\text {losses }}^{\prime \prime}\right)$

H-TRIS ensures sufficient spatial separation between the radiant panels and the exposed surface of the test specimen to avoid imposition of vitiated air near the surface of a burning specimen, thus supporting the assumptions used in the inverse modelling procedures and that gases at the exposed surface of the test specimen are not unduly influenced by forced convection from the radiant panels [34].

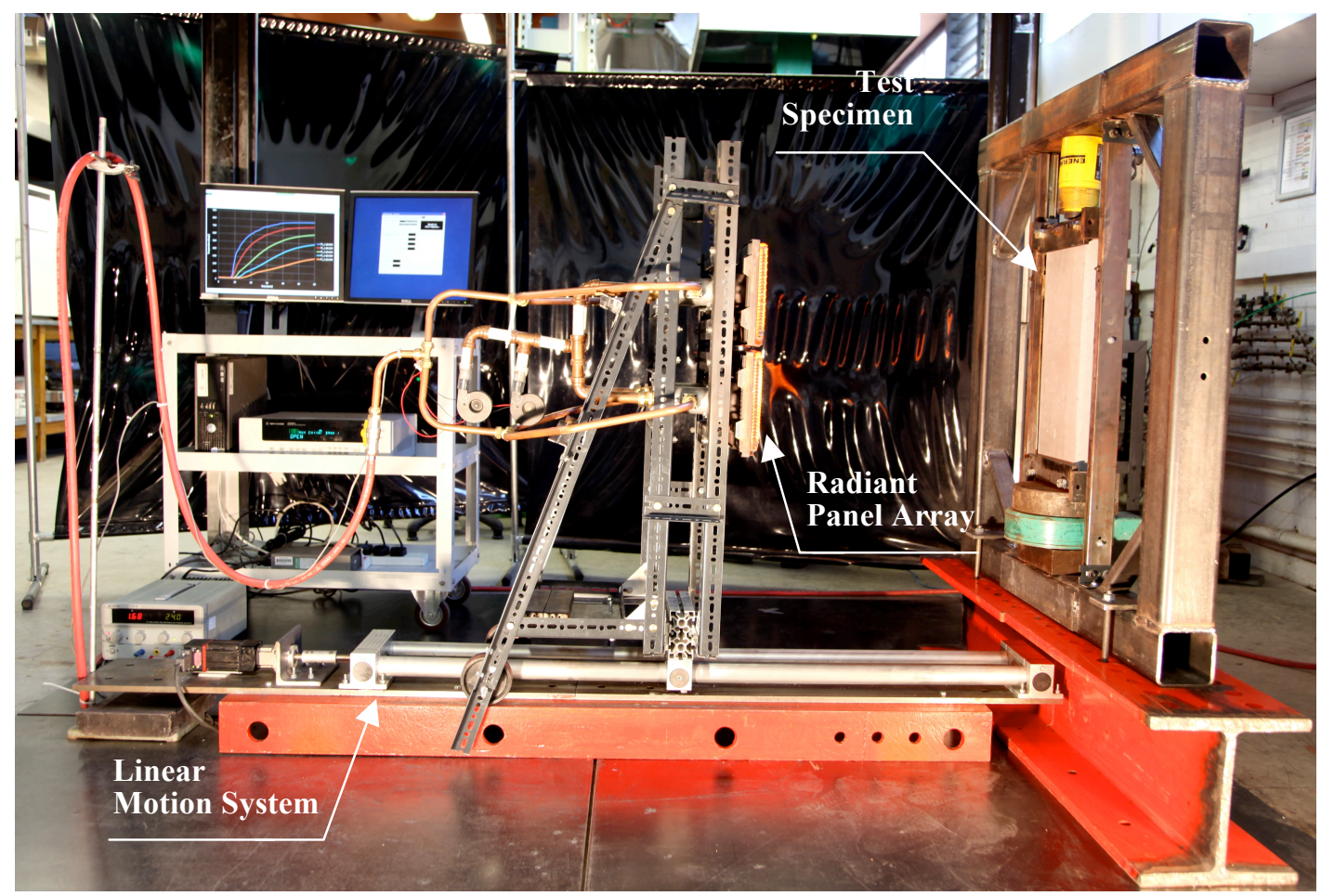

Figure 3 - Photograph of H-TRIS v1.0 (side elevation) [33]. 


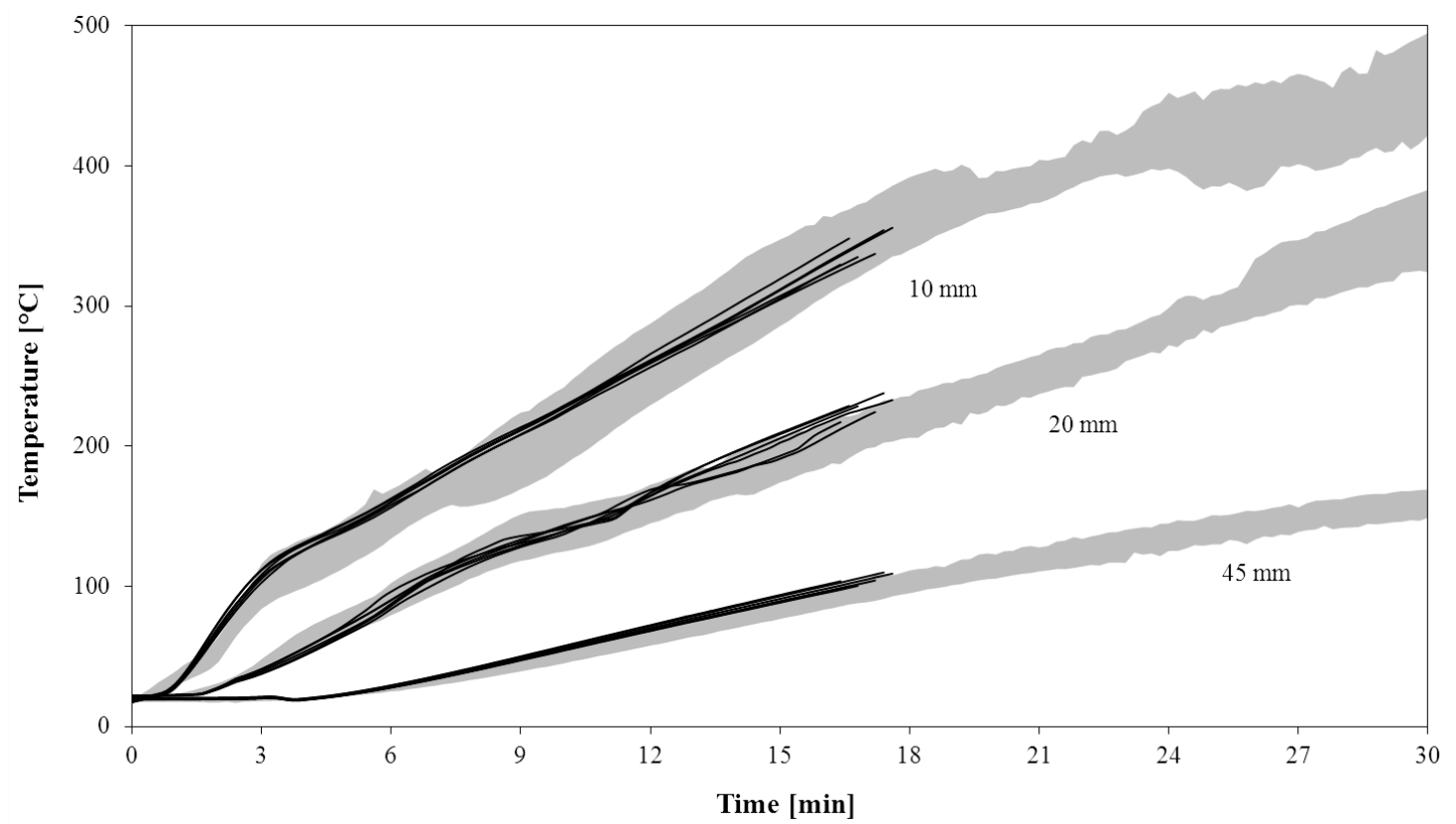

Figure 4 - In-depth temperature measurements taken during a standard fire resistance test [32] compared against those made with H-TRIS (shaded areas show the spread of temperatures measured during a single fire resistance test, black lines show measurements with H-TRIS).

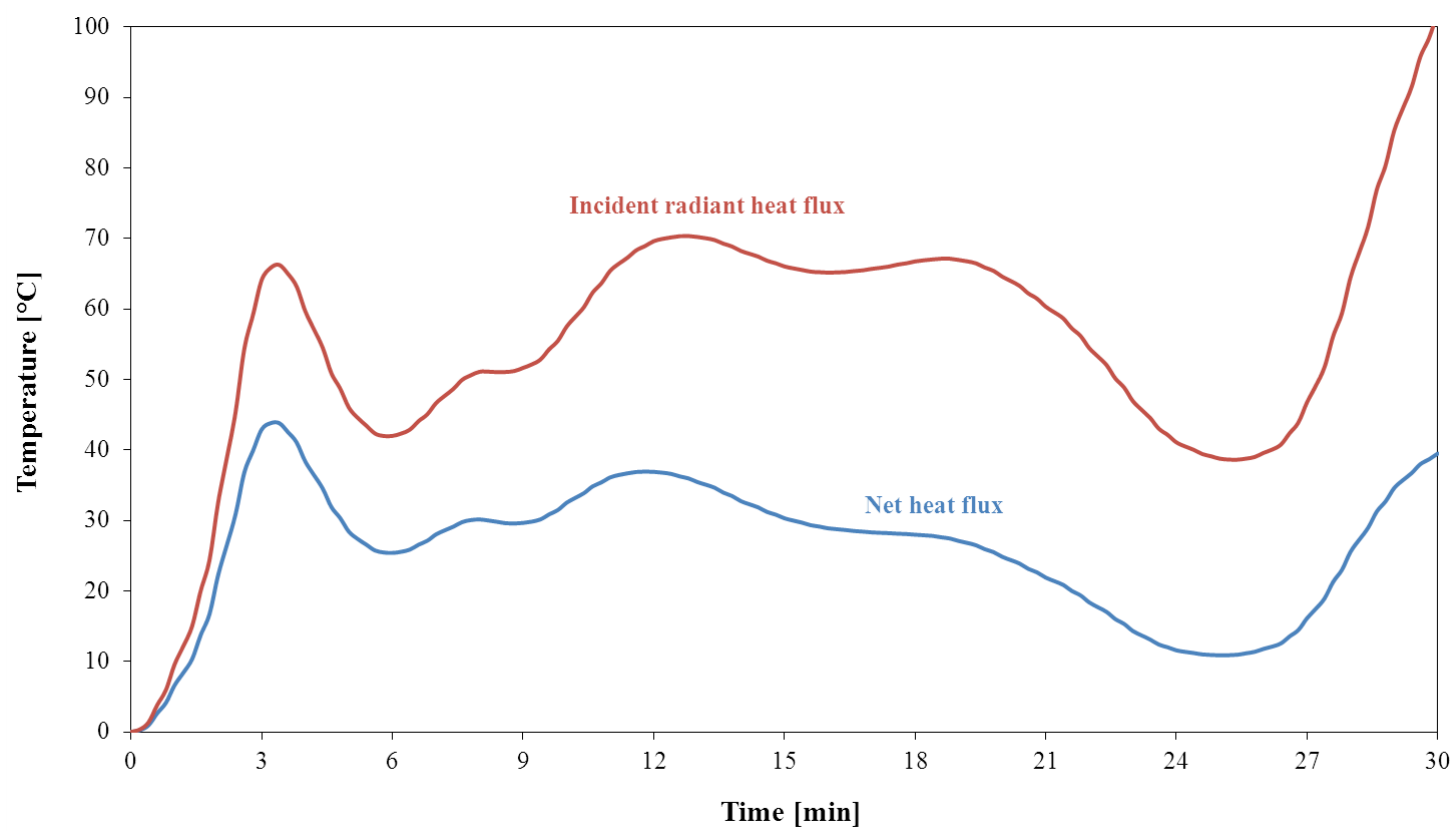

Figure 5 - Time-history of net heat flux experienced by test specimens during a standard fire resistance test, and calibrated required incident radiant heat flux imposed within H-TRIS to yield an equivalent net heat flux at the exposed surface of the test specimen (from inverse modelling). 


\section{EXPERIMENTAL PROGRAM}

205 Constrained by practical requirements on minimum compressive strength and self206 compaction of the concrete mixes; the concrete compressive strength (C90 according to [35])

207 and workability (slump flow of $750 \mathrm{~mm}$ according to [36]) were maintained constant for all 208 concrete mixes studied. Parameters varied amongst the 11 concrete mixes were:

209 - PP fibre cross-section (18 or $32 \mu \mathrm{m}$ diameter circular cross-sections, and $37 \times 200 \mu \mathrm{m}^{2}$

210 rectangular cross-sections);

211 - PP fibre length $(3,6,12$, or $20 \mathrm{~mm})$;

212 - PP fibre supplier (three manufacturers);

213 - PP fibre type (monofilament, multifilament, or fibrillated); and

214 - dose (between 0.68 and $2.34 \mathrm{~kg}$ of PP fibres per $\mathrm{m}^{3}$ of concrete).

215 Mix labels shown in Table 1 and Table 2 have no inherent meaning but were defined by the

216 industrial partner based on an in-house mix numbering scheme. Specific PP fibre suppliers

217 are named purely for the purposes of factual accuracy. The fibre doses given in Table 1 were 218 chosen to provide, to the extent possible, like-for-like comparisons assessing: (1) the fibre

219 dose (i.e. total fibre mass), (2) the total fibre surface area, (3) the total fibre length, (4) the

220 total number of individual fibres per unit volume of concrete; all while maintaining consistent

221 compressive strength and self-consolidating properties. 
Table 1 - Description of PP fibres included in the concrete mixes evaluated.

\begin{tabular}{|c|c|c|c|c|c|c|c|}
\hline \multirow[b]{2}{*}{$\begin{array}{c}\text { Mix } \\
\text { Label }\end{array}$} & \multicolumn{3}{|c|}{ PP Fibre Parameters } & \multicolumn{4}{|c|}{ Like-for-like Comparison } \\
\hline & $\begin{array}{c}\text { Supplier } \\
\text { (type) }\end{array}$ & $\begin{array}{l}\text { Cross- } \\
\text { section }\end{array}$ & Length & $\begin{array}{c}\text { Dose } \\
{\left[\mathrm{kg} / \mathrm{m}^{3}\right]}\end{array}$ & $\begin{array}{c}\text { Total fibre } \\
\text { surface area } \\
{\left[\mathrm{m}^{2} / \mathbf{m}^{3}\right]}\end{array}$ & $\begin{array}{c}\text { Total fibre } \\
\text { length } \\
{\left[\mathbf{k m} / \mathbf{m}^{3}\right]}\end{array}$ & $\begin{array}{l}\text { Total number of } \\
\text { individual fibres } \\
{\left[\text { mill. of fibres } / \mathrm{m}^{3}\right]}\end{array}$ \\
\hline 042* & \multicolumn{3}{|c|}{ None } & & - & - & - \\
\hline 132 & \multirow{2}{*}{$\begin{array}{l}\text { Bekaert }^{\mathrm{a}} \\
\text { (monofilament) }\end{array}$} & $18 \mu \mathrm{m}$ & \multirow{2}{*}{$6 \mathrm{~mm}$} & 0.68 & 165 & 2915 & 486 \\
\hline 142 & & $32 \mu \mathrm{m}$ & & 1.20 & 165 & 1640 & 273 \\
\hline \multirow{2}{*}{$\begin{array}{l}341 * \\
342\end{array}$} & \multirow{5}{*}{$\begin{array}{l}\text { Propex }^{\mathrm{b}} \\
\text { (multifilament) }\end{array}$} & \multirow{5}{*}{$32 \mu \mathrm{m}$} & \multirow{2}{*}{$3 \mathrm{~mm}$} & 1.20 & 165 & 1640 & 547 \\
\hline & & & & 2.00 & 275 & 2733 & 911 \\
\hline 345 & & & \multirow{2}{*}{$6 \mathrm{~mm}$} & 1.20 & 165 & 1640 & 273 \\
\hline 343 & & & & 1.40 & 192 & 1913 & 319 \\
\hline 344 & & & $12 \mathrm{~mm}$ & 1.20 & 165 & 1640 & 137 \\
\hline 241* & \multirow{3}{*}{$\begin{array}{l}\text { Vulkan }^{\mathrm{c}} \\
\text { (fibrillated) }\end{array}$} & \multirow{3}{*}{$\begin{array}{c}37 \times 200 \\
\mu \mathrm{m}^{2}\end{array}$} & \multirow{3}{*}{$20 \mathrm{~mm}$} & 1.20 & 84 & 178 & 15 \\
\hline $242 *$ & & & & 2.00 & 141 & 297 & 25 \\
\hline 243 & & & & 2.34 & 165 & 348 & 29 \\
\hline
\end{tabular}

*Concrete mixes for which spalling occurred during testing.

${ }^{\text {a }}$ www.bosfa.com/products/duo-mix-fire.aspx

${ }^{\mathrm{b}}$ www.fibermesh.com/product/microsynthetic.html

${ }^{c}$ www.en.krampeharex.com/pdf/Kunststofffaser_PF.pdf

225 Table 2 - Description of the constituents and properties of the concrete mixes evaluated.

\begin{tabular}{|c|c|c|c|c|c|c|c|}
\hline \multirow{3}{*}{$\begin{array}{c}\text { Mix } \\
\text { Label }\end{array}$} & \multirow{2}{*}{ Water/Cement ${ }^{1}$} & \multirow{2}{*}{$\begin{array}{l}\text { Limestone } \\
\text { aggregate } \\
(0-8 \mathrm{~mm})\end{array}$} & \multirow{2}{*}{$\begin{array}{c}\text { Super- } \\
\text { plasticizer }\end{array}$} & \multirow{2}{*}{$\begin{array}{c}\text { Slump flow } \\
{[36]}\end{array}$} & \multirow{2}{*}{$\begin{array}{c}\text { Moisture } \\
\text { content at } \\
\text { testing }\end{array}$} & \multicolumn{2}{|c|}{$\begin{array}{l}\text { Compressive strength } \\
\text { (Standard deviation) }\end{array}$} \\
\hline & & & & & & 28 days & 6 months \\
\hline & {$[-]$} & {$\left[\mathrm{kg} / \mathrm{m}^{3}\right]$} & [\% of cement] & {$[\mathrm{mm}]$} & {$[\%]$} & [MPa] & [MPa] \\
\hline 042* & 0.33 & 1745 & $1.73 \%$ & 808 & $4.5 \%$ & $101(1.6)$ & $106(1.3)$ \\
\hline 132 & 0.32 & 1710 & $1.70 \%$ & 740 & $4.4 \%$ & $95(1.1)$ & $105(0.7)$ \\
\hline 142 & 0.31 & 1708 & $1.71 \%$ & 745 & $4.3 \%$ & $95(2.7)$ & $109(0.3)$ \\
\hline $341 *$ & 0.32 & 1716 & $1.67 \%$ & 800 & $4.0 \%$ & $103(0.8)$ & $112(0.6)$ \\
\hline 342 & 0.33 & 1726 & $1.73 \%$ & 765 & $4.6 \%$ & $98(2.1)$ & $107(1.1)$ \\
\hline 345 & 0.31 & 1715 & $1.72 \%$ & 758 & $4.5 \%$ & $104(0.6)$ & $108(0.6)$ \\
\hline 343 & 0.32 & 1711 & $1.71 \%$ & 740 & $4.3 \%$ & $99(1.0)$ & $105(0.9)$ \\
\hline 344 & 0.31 & 1711 & $1.73 \%$ & 740 & $4.5 \%$ & $101(0.4)$ & $108(0.7)$ \\
\hline $241 *$ & 0.31 & 1724 & $1.65 \%$ & 765 & $4.0 \%$ & $103(0.6)$ & $106(0.6)$ \\
\hline $242 *$ & 0.35 & 1729 & $1.73 \%$ & 740 & $5.0 \%$ & $94(1.1)$ & $108(0.5)$ \\
\hline 243 & 0.33 & 1685 & $1.68 \%$ & 680 & $4.6 \%$ & $95(1.4)$ & $103(0.4)$ \\
\hline
\end{tabular}

${ }^{1}$ Cement constituents: $64 \%$ Portland cement, 16\% microsilica, 20\% fly ash.

*Concrete mixes for which spalling occurred during testing. 


\subsection{Test specimens}

227 Medium-scale unreinforced and unstressed concrete specimens were tested using H-TRIS in a vertical orientation with heating from one side. Recognising that scaling of test specimens in structural fire resistance testing is debated on various grounds [7], the dimensions of the specimens in the direction of the principal heat flow were taken as the same as those used for

231 the prior large-scale furnace test specimens [32]. Thus, medium-scale specimens had $45 \times$ $232200 \mathrm{~mm}^{2}$ cross-sections and an overall length of $500 \mathrm{~mm}$ (due to space limitations within $\mathrm{H}$ TRIS). Cold overhangs (i.e. unheated ends) with a length of $50 \mathrm{~mm}$ were required due to specimen holding and loading considerations; thus the thermally exposed surface was $400 \times$ $200 \mathrm{~mm}^{2}$, as shown in Figure 6.

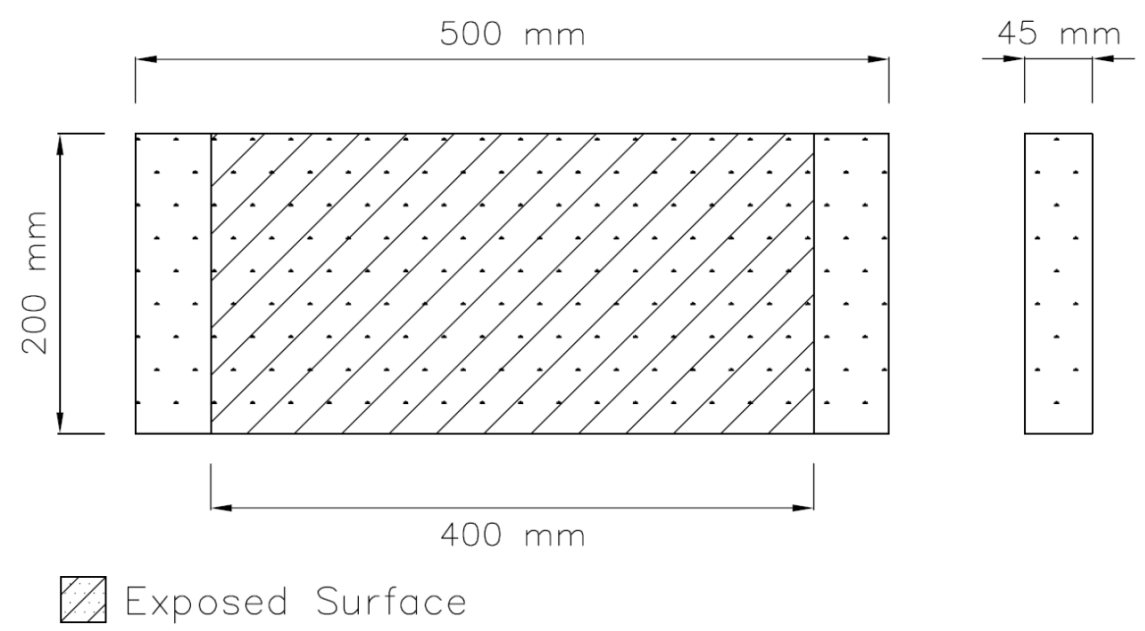

Figure 6 - Plan and section views of concrete specimens tested with H-TRIS.

\subsubsection{Casting and curing process}

239 Specimens were cast in the production facilities of the industry partner. The mixing and

240 casting procedures were performed according the standards for typical precast concrete

241 elements fabricated by the industry partner. While the parameters of the concrete mixes were

242 predefined, as shown in Table 2, maintaining certain key parameters unchanged, mild 
243 variations during the concrete mixing process were required to attain the optimum self-

244 compacting characteristics required for constructability (i.e. a minimum slump flow of about

$245750 \mathrm{~mm}$ ). This was mainly attributed to the variable (and uncontrolled) conditions during

246 casting (e.g. moisture content of the aggregates used, ambient temperature, ambient humidity,

247 etc.); however these changes are not considered relevant for the current study. Constituents

248 and slump flow values [36] for the various concrete mixes are given in Table 2.

249 After casting in Switzerland, specimens were covered with polyethylene sheeting for 48

250 hours before stripping the forms, and were cured in moist conditions under polyethylene

251 sheets for a further 3 to 5 months before being delivered to the UK for testing. They were 252 then stored in a conditioning room at $20^{\circ} \mathrm{C}$ and $80 \%$ relative humidity (RH) until testing. All

253 specimens were tested at an age between 13 and 16 months from casting.

254 Cubes $(150 \mathrm{~mm})$ were cast for compressive strength and average moisture content 255 measurements and kept under identical curing conditions. The average moisture content of 256 the test specimens at the time of testing was between 4.0 and $5.0 \%$ by mass; these

257 measurements being made by dehydration mass loss. Compressive strengths at 28 days and 6 258 months were between 93 and $112 \mathrm{MPa}$ [35]. Table 2 presents the moisture and compressive 259 strength measurements for each of the specific mixes.

\subsection{Test procedure}

261 As previously explained, H-TRIS was programmed to impose a thermal boundary condition

262 equivalent to that experienced by the large-scale concrete specimens tested during standard

263 fire resistance tests [32]. Figure 5 shows the time-history of incident radiant heat flux 264 yielding an equivalent time-history of net heat flux, and hence equivalent in-depth 265 temperature distributions as experienced during the fire resistance tests. 
266 The maximum possible incident radiant heat flux that could be achieved in H-TRIS v1.0 is

$267100 \mathrm{~kW} / \mathrm{m}^{2}$. The desired time-history of incident radiant heat flux shown in Figure 5 was

268 therefore imposed until the maximum incident radiant heat flux of $100 \mathrm{~kW} / \mathrm{m}^{2}$ was reached;

269 beyond this point it was maintained constant at $100 \mathrm{~kW} / \mathrm{m}^{2}$. Because the objective of the

270 study was to examine the spalling behaviour (or more specifically, the occurrence of the first

271 spalling event), rather than to develop a deep understanding of the specific mechanisms

272 involved, tests with H-TRIS were continued only until first spalling event occurred; if no

273 spalling occurred within 60 minutes the test was halted, since heat-induced explosive spalling

274 is unlikely at late stages [7].

275 It was desired to also examine the effect of pre-compressive stresses on propensity for 276 spalling during testing. Mechanical loading and boundary conditions were imposed using a 277 purpose built loading rig (see figures 3 and 7), designed to impose a sustained axial compressive loading on the test specimens during heating, hence replicating the precompression that would be experienced by prestressed concrete specimens manufactured

280 from similar concrete mixes (recall that the specimens tested with H-TRIS were unreinforced 281 and un-prestressed, however the end use applications envisioned for these mixes are typically

282 precast, prestressed). For reasons described elsewhere [32], the loading in H-TRIS aimed to 283 replicate the conditions near the ends of the prestress transfer zones of prestressed HPC specimens with nominally concentric prestressing forces (i.e. with prestressing at mid-depth).

Specimens were tested either under a free-to-expand (unrestrained) condition or under sustained compressive load. Based on prior research [7], the service pre-compressive stress

287 within the concrete at the end of a prestress transfer zone was conservatively defined as 12.3

288 MPa (i.e. prestressing losses due to elastic shortening, shrinkage, creep effects, and thermally induced prestressing forces were neglected). Therefore, the sustained axial compressive load 
applied on specimens tested in H-TRIS, which has cross-sectional areas of $9000 \mathrm{~mm}^{2}(200 \times$

$29145 \mathrm{~mm})$, was:

$292 L_{c, 0}=12.3[\mathrm{MPa}] \cdot 9000\left[\mathrm{~mm}^{2}\right]=110.7[\mathrm{kN}]$

293 This concentric compressive load, $L_{c, 0}$, was applied using notionally rotationally fixed-fixed 294 end conditions. Load was held constant for the duration of the tests using a hydraulic load 295 control system (i.e. the applied compressive load was maintained, counteracting potential 296 effects from thermal expansion and elastic modulus changes of the test specimen during 297 heating). Unloaded test specimens were left free-to-expand (under notionally rotationally 298 fixed-fixed end conditions) during heating. All tests were performed in triplicate for each 299 specific concrete mix and restraint condition.

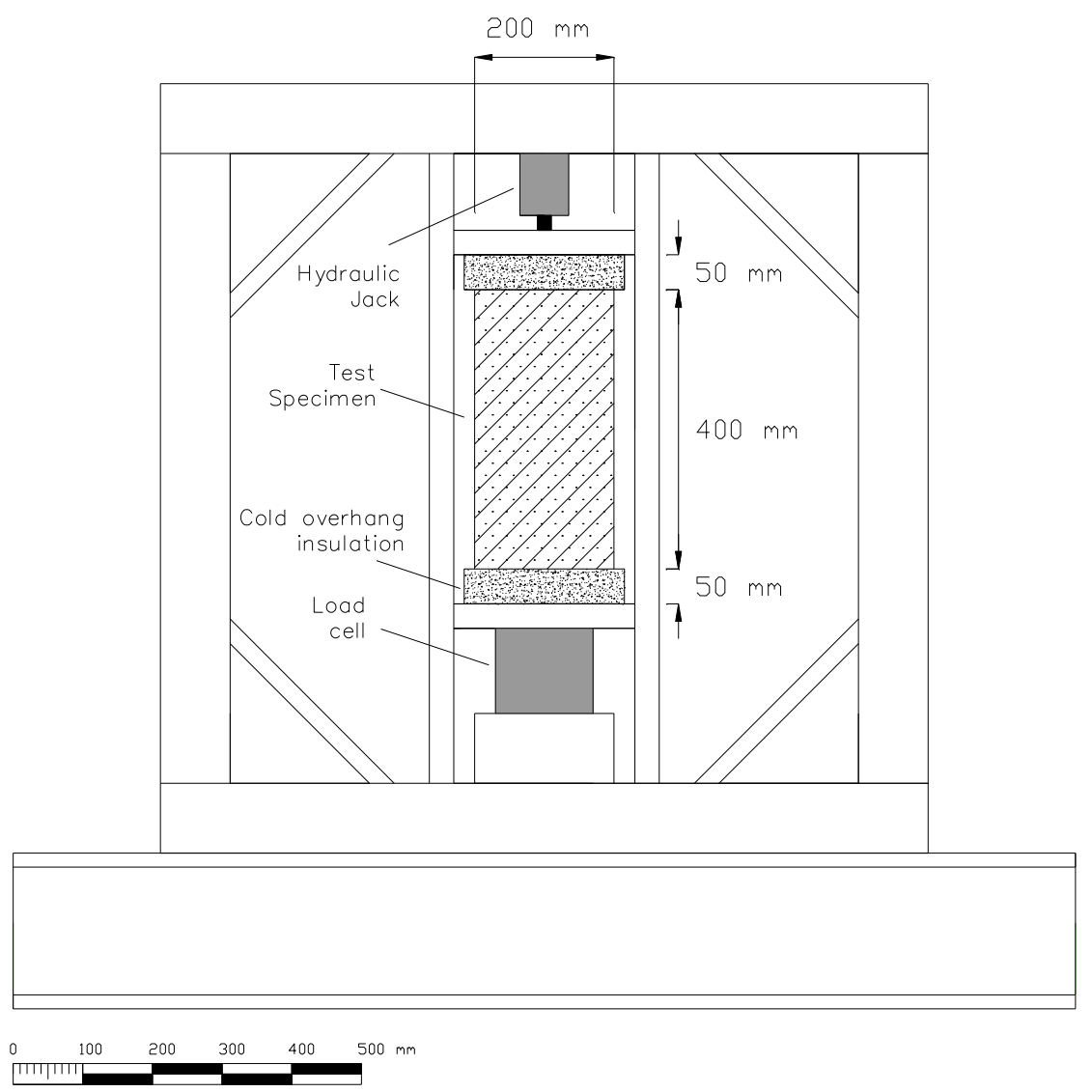

$301 \quad$ Figure 7 - Schematic showing the mechanical loading rig used in H-TRIS testing (front elevation). 


\subsection{Assessment of spalling}

303 With a few exceptions (e.g. [37]), the propensity and extent of concrete spalling during fire

304 tests is traditionally assessed only by visual evaluation of the specimens' exposed surface,

305 and occasionally by measuring the depth, volume, or mass of spalled concrete. Testing with

306 H-TRIS allows a more careful quantification of time-to-spalling, the mass of concrete

307 spalled, and the total net heat density up to the moment of first spalling; this is calculated as

308 the area under the time versus net heat flux curve divided by the area of the exposed surface.

\section{TEST RESULTS AND ANALYSIS}

310 Sixty-six individual spalling tests were performed during a period of 30 days; thus

311 demonstrating the low temporal costs of the H-TRIS testing approach as compared with

312 traditional furnace testing; this number of tests would have taken months using a standard fire

313 testing furnace.

314 It is noteworthy that (contrary to expectations and contrary to most prior research on spalling

315 performed in furnaces), when spalling occurred for a given mix tested in H-TRIS it occurred

316 for all three identical repeat tests, and at similar heating exposure times. Likewise, if no

317 spalling was observed for a particular mix with H-TRIS then this was true for all three repeat

318 tests. Figure 8 shows typical post-test photographs of H-TRIS test specimens showing

319 increasing severities of spalling.

320 Spalling occurred for four of the 11 concrete mixes, namely: 042, 341, 241, and 242 (refer to

321 tables 1 and 2). None of the other mixes experienced any spalling whatsoever for the full

322 duration of the 60 minute tests. A summary of the relevant test results for the concrete mixes

323 that experienced spalling is given in Table 3 (non-spalling mixes are not included). 


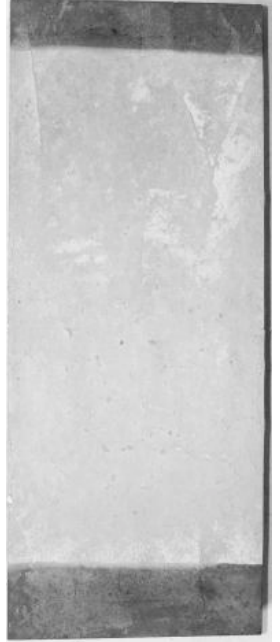

Mix 342

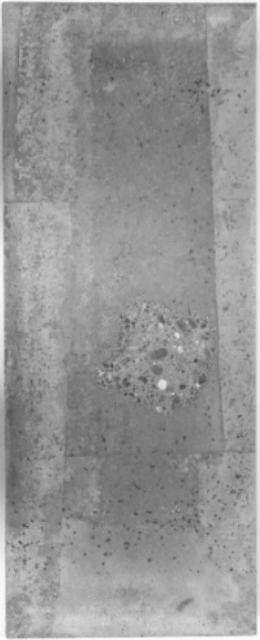

Mix 241

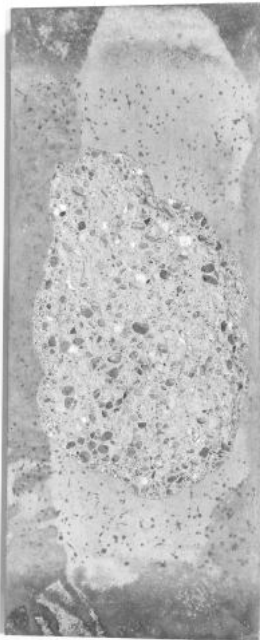

Mix 242

(1503 g spalled)

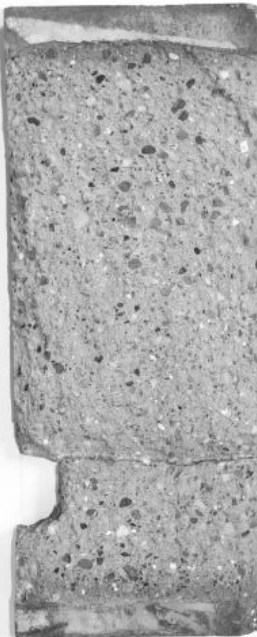

Mix 341

(3095 g spalled)

Figure 8 - Post-test photographs of specimens tested with H-TRIS [38]. 
Table 3 - Experimental test matrix and results for spalled specimens tested with H-TRIS.

\begin{tabular}{|c|c|c|c|c|c|c|}
\hline \multirow{2}{*}{ Mix } & \multirow{2}{*}{$\begin{array}{l}\text { Sustained } \\
\text { compressive } \\
\text { stress }\end{array}$} & \multirow{2}{*}{$\begin{array}{l}\text { Time to } \\
\text { spalling } \\
\text { [min] }\end{array}$} & \multirow{2}{*}{$\begin{array}{l}\text { Net Heat } \\
\text { Density } \\
{\left[\mathrm{kJ} / \mathrm{cm}^{2}\right]}\end{array}$} & \multicolumn{2}{|c|}{ Mass spalled $^{1}$} & \multirow{2}{*}{$\begin{array}{c}\text { Mass spalled } \\
/ \text { net heat density } \\
{\left[\mathrm{g} \times \mathrm{cm}^{2} / \mathrm{kJ}\right]}\end{array}$} \\
\hline & & & & {$[\mathrm{g}]$} & {$[\%]$} & \\
\hline \multirow{6}{*}{042} & \multirow{3}{*}{$0 \mathrm{MPa}$} & 10.9 & 2.28 & 208 & $2.0 \%$ & 91 \\
\hline & & 24.7 & 5.99 & 664 & $6.3 \%$ & 111 \\
\hline & & 13.9 & 3.01 & 1135 & $10.7 \%$ & 377 \\
\hline & \multirow{3}{*}{$12.3 \mathrm{MPa}$} & 12.5 & 2.66 & 1281 & $12.1 \%$ & 481 \\
\hline & & 11.0 & 2.31 & 679 & $6.3 \%$ & 294 \\
\hline & & 13.1 & 2.81 & 1189 & $11.2 \%$ & 424 \\
\hline \multirow{6}{*}{341} & \multirow{3}{*}{$0 \mathrm{MPa}$} & 17.1 & 3.85 & 923 & $8.4 \%$ & 240 \\
\hline & & 14.6 & 3.19 & 268 & $2.4 \%$ & 84 \\
\hline & & 16.5 & 3.67 & 435 & $4.0 \%$ & 118 \\
\hline & \multirow{3}{*}{$12.3 \mathrm{MPa}$} & 16.3 & 3.64 & 3095 & $28.5 \%$ & 850 \\
\hline & & 13.0 & 2.80 & 2043 & $18.7 \%$ & 731 \\
\hline & & 14.4 & 3.16 & 2645 & $24.4 \%$ & 838 \\
\hline \multirow{6}{*}{241} & \multirow{3}{*}{$0 \mathrm{MPa}$} & 12.4 & 2.66 & 420 & $3.8 \%$ & 158 \\
\hline & & 7.9 & 1.61 & 100 & $0.9 \%$ & 62 \\
\hline & & 11.7 & 2.49 & 238 & $2.2 \%$ & 96 \\
\hline & \multirow{3}{*}{$12.3 \mathrm{MPa}$} & 7.3 & 1.48 & 251 & $2.3 \%$ & 169 \\
\hline & & 14.3 & 3.11 & 210 & $1.9 \%$ & 67 \\
\hline & & 12.5 & 2.66 & 784 & $7.2 \%$ & 294 \\
\hline \multirow{6}{*}{242} & & - & - & - & - & - \\
\hline & $0 \mathrm{MPa}$ & - & - & - & - & - \\
\hline & & - & - & - & - & - \\
\hline & \multirow{3}{*}{$12.3 \mathrm{MPa}$} & $9.9^{2}$ & 2.07 & 438 & $4.1 \%$ & 212 \\
\hline & & $9.4^{2}$ & 1.93 & 423 & $4.0 \%$ & 219 \\
\hline & & $10.6^{2}$ & 2.22 & 1503 & $14.3 \%$ & 678 \\
\hline
\end{tabular}

${ }^{1}$ Mass spalled was calculated by subtracting the mass of the tested specimen (after cooling) from the initial mass of the specimen. Note that no distinction is made between mass lost due to the spalled concrete and that due to dehydration of the specimen during heating.

${ }^{2}$ Large-scale prestressed specimens tested during standard fire resistance tests [32] spalled during the first 9.2 to 10.3 minutes from the start of the test. 


\subsection{Assessment of spalling}

330 When testing using H-TRIS it is possible to accurately quantify the time-to-spalling, the mass 331 spalled, and the accumulated net heat density. All three quantifiable metrics are described 332 below.

\subsubsection{Time-to-spalling}

334 During the tests described herein, when heat-induced spalling of concrete occurred it was 335 always between 7 and 25 minutes from the start of the test (refer to Table 3). This being said, 336 time-to-spalling demonstrated no obvious correlations with other parameters investigated 337 herein.

338 The occurrence of heat-induced concrete spalling was in reasonable agreement in terms of 339 time-to-spalling (i.e. \pm 2 minutes) with specimens cast from identical concrete mixes and 340 tested during the aforementioned large-scale fire resistance tests [32] (refer to Table 3). This

341 observation provides further credence to H-TRIS' ability to accurately replicate not only the

342 in-depth time dependent temperature distributions experienced by concrete specimens during 343 standard fire resistance tests, but also the time-to-spalling during repeat testing of identical 344 specimens under identical thermal boundary and loading/restraint conditions.

\subsubsection{Mass spalled}

346 Specimens' masses were measured before and after each test. For tests where spalling 347 occurred the mass lost as a consequence of the spalling event and dehydration was calculated 348 by subtracting the mass of the tested specimen (after cooling) from the initial mass of the 349 specimen. It is noteworthy that no distinction was made between mass lost due to the spalled 350 concrete and the mass lost due to dehydration of the specimen during heating. 
351 Figure 9 shows the percentage of mass spalled plotted against the time-to-spalling for tests under a free-to-expand condition and under sustained compressive stress. Whilst the trend is not categorical, in most cases the test results indicate that when spalling occurs at an early

354 stage of the test the mass spalled is lower than when it occurs at a later stage. For example, an exception to the aforesaid trend was observed for one of the test specimens cast with Mix 042 (no PP fibres), which spalled after 25 minutes from the start of the test and showed a relatively low percentage of mass spalled (refer to Table 3 and Figure 9). This may be associated with the fact that longer heating periods result in higher amounts of accumulated thermal (and thermo-mechanical) energy, which predictably results in more energy being released upon spalling; thus more concrete mass spalled.

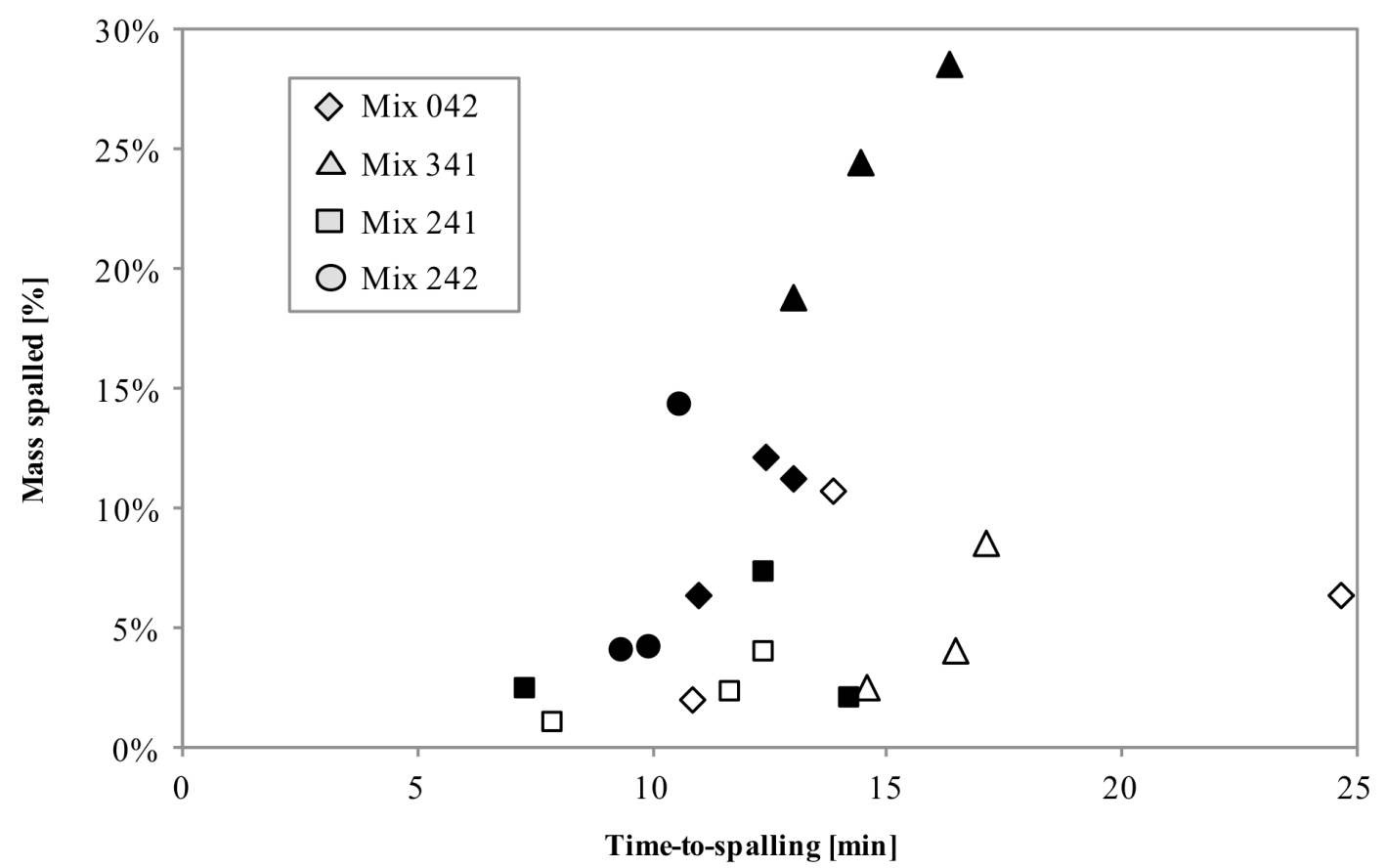

Figure 9 - Percentage of mass spalled versus time-to-spalling for tests in free-to-expand condition (filled markers) and tests under sustained compressive stress (empty markers).

\subsubsection{Accumulated net heat density}

365 The ratio of mass spalled to accumulated net heat density was calculated for each of the spalled test specimens (refer to Table 3). This ratio could potentially allow for rational, 
367 quantifiable comparison between spalling events for concrete specimens tested under 368 different thermal boundary conditions. Although this variable heat flux comparison was not

369 carried out in the current study, the concept is first introduced here and will be used in future 370 studies in which the effect of different thermal boundary conditions is evaluated using H371 TRIS.

\subsection{Parametric analysis}

373 This section presents a parametric assessment performed for each of the PP fibre parameters

374 varied within the current study, with reference to Table 1.

\subsubsection{PP fibre cross-section}

376 As is widely recognized by concrete manufacturers and researchers (e.g. $[24,31])$, during the 377 casting process it was observed that PP fibres with a small cross-sections (i.e. $18 \mu \mathrm{m}$ diameter) had a strong undesirable effect on the self-compacting and workability of the fresh concrete mixes, thus the required slump flow was attained only for a relatively low dose of these smaller cross-section fibres (refer to Table 1). For instance, similar slump flow was achieved for two mixes, 132 and 142, respectively. Mix 132 included $0.68 \mathrm{~kg}$ of $18 \mu \mathrm{m}$

382 diameter PP fibres per $\mathrm{m}^{3}$ of concrete and had a slump flow of $740 \mathrm{~mm}$, whereas Mix 142

383 had a slump flow of $745 \mathrm{~mm}$ with a larger dose of $1.20 \mathrm{~kg}$ of $32 \mu \mathrm{m}$ diameter PP fibres per

$384 \mathrm{~m}^{3}$ of concrete (refer to Table 2). Mix 142 thus had almost double the dose (by mass) of PP 385 fibres, while all other parameters (e.g. PP fibre length, supplier, type, etc.) were unchanged 386 (refer to Table 1).

387 No spalling was observed for mixes 132 or 142 (both mixes including $6 \mathrm{~mm}$ long 388 monofilament PP fibres), thus no direct comparisons were possible to evaluate the influence of cross-section on spalling for identical monofilament PP fibres with circular cross-sections 
390 of 18 or $32 \mu \mathrm{m}$ in diameter. Nonetheless, it appeared that including $0.68 \mathrm{~kg}$ per $\mathrm{m}^{3}$ of $18 \mu \mathrm{m}$ 391 diameter PP fibres was 'as effective' as including $1.20 \mathrm{~kg}$ per $\mathrm{m}^{3}$ of $32 \mu \mathrm{m}$ diameter fibres for

392 the time history of heat flux considered in the current study (simulating the exposure during a 393 standard fire resistance test [32]).

394 Concrete specimens cast with mixes including fibrillated PP fibres with comparatively large $39537 \times 200 \mu \mathrm{m}^{2}$ rectangular cross-sections (i.e. mixes 241, 242 and 243 ) demonstrated a high 396 occurrence of spalling, although a 'recommended' [35] dose of PP fibres was included (i.e. $3972.00 \mathrm{~kg}$ of PP fibres per $\mathrm{m}^{3}$ in Mix 242). Test specimens cast with Mix $241(1.20 \mathrm{~kg}$ of PP 398 fibres per $\mathrm{m}^{3}$ ) spalled both when tested under sustained compressive stress and under free-to399 expand conditions (refer Table 3). Specimens cast with Mix 242 (2.00 kg of PP fibres per

$400 \mathrm{~m}^{3}$ ), equivalent to that for casting of large-scale prestressed specimens tested in a standard 401 fire resistance test [32] only spalled when under sustained compressive stress; unstressed 402 specimens did not spall. Specimens cast with Mix $243\left(2.34 \mathrm{~kg}\right.$ of PP fibres per $\mathrm{m}^{3}$ of 403 concrete) did not spall under any condition.

\subsubsection{PP fibre length}

405 A comparison was made to assess the influence on spalling of individual PP fibre length for 406 concrete mixes 341, 345, and 344, all of which included $1.20 \mathrm{~kg}$ of PP fibres per $\mathrm{m}^{3}$ of 407 concrete (32 $\mu \mathrm{m}$ in diameter multifilament PP fibres) with PP fibre lengths of 3, 6 and 12 $408 \mathrm{~mm}$, respectively (refer to Table 1). Spalling was observed for all specimens with $3 \mathrm{~mm}$ long 409 PP fibres (refer to Table 3), which suggests a negative influence of using very short PP fibres, 410 thus supporting the theoretical findings from prior studies; relatively short PP fibres fail to 411 generate so-called continuous channels (refer to Section 1.2) for enhancing moisture 412 migration during heating thought $[4,31]$. For the current study, $3 \mathrm{~mm}$ long PP fibres were 413 considered because of their reduced influence on the workability of fresh concrete. Very long 
414 PP fibres have a clear negative impact on the self-compacting and workability properties of

415 fresh concrete; i.e. at an equivalent dose the use of longer PP fibres results in lower measured

416 slump flow (refer to Table 2). No spalling was observed for either of the other two mixes,

417 providing no clear comparative data for $6 \mathrm{~mm}$ versus $12 \mathrm{~mm}$ long PP fibres.

\section{$418 \quad$ 5.2.3 PP fibre supplier}

419 The PP fibre suppliers whose products were assessed in this study were Bekaert, Propex, and 420 Vulkan. No spalling was observed for mixes 142 and 345 cast with an equivalent dose (1.20 $421 \mathrm{~kg}$ of PP fibres per $\mathrm{m}^{3}$ of concrete) of basically identical PP fibres from different suppliers

422 (32 $\mu \mathrm{m}$ diameter, $6 \mathrm{~mm}$ long monofilament and multifilament PP fibres); hence, as expected, 423 no influence was observed for the comparison made between these essentially identical 424 concrete mixes.

\subsubsection{PP fibre type}

426 Concrete mixes which included monofilament or multifilament PP fibres showed a lower 427 propensity for heat-induced concrete spalling relative to those cast with fibrillated PP fibres. 428 This may not only be associated to the type of PP fibre but to the significantly larger cross429 section of the fibrillated PP fibres (refer to Table 1); hence the inevitably lower specific surface area of individual fibres (discussed in Section 5.3.2).

\subsubsection{Sustained compressive stress}

432 For mixes in which spalling occurred under sustained compressive stress, spalling also 433 occurred under free-to-expand conditions; with the exception of Mix 242 (refer to Table 3)

434 which did not spall under a free-to-expand condition but spalled in all cases when under 435 sustained compressive stress. This corroborates that widely stated belief that stressed concrete 436 is more likely to spall than unstressed concrete, all other factors being equal. 


\subsection{Like-to-like comparisons}

438 In addition to the parametric analysis presented herein, three additional parameters associated 439 with the inclusion of PP fibres were compared on a like-to-like basis (refer to Table 1).

\subsubsection{Dose of PP fibres}

441 The concrete mixes examined in the current study had a range of doses between 0.68 and $2.34 \mathrm{~kg}$ of PP fibres per $\mathrm{m}^{3}$ of concrete. An explicit comparison between specific mixes (refer

443 to Table 1) was carried out to assess the influence of PP fibre dose (keeping all other 444 parameters constant) on the occurrence of spalling:

445 - Mixes 341 (spalled) and 342 (did not spall) included 1.20 and $2.00 \mathrm{~kg}$ of PP fibres per $446 \mathrm{~m}^{3}$, respectively (multifilament fibres $32 \mu \mathrm{m}$ in diameter and $3 \mathrm{~mm}$ long).

- Mixes 345 and 343 (neither of which spalled) included 1.20 and $1.40 \mathrm{~kg}$ of PP fibres per $\mathrm{m}^{3}$, respectively (multifilament fibres $32 \mu \mathrm{m}$ in diameter and $6 \mathrm{~mm}$ long).

- Mixes 241 (spalled), 242 (spalled only when loaded), and 243 (did not spall) included $1.20,2.00$ and $2.34 \mathrm{~kg}$ of PP fibres per $\mathrm{m}^{3}$, respectively (fibrillated fibres with $37 \times 200$ $\mu \mathrm{m}$ rectangular cross-section and $20 \mathrm{~mm}$ long).

452 It is noteworthy that spalling occurred for all test specimens cast from Mix 042, which had no

453 PP fibres (refer to Table 1). As expected, a higher dose of PP fibres resulted in a lower 454 propensity for heat-induced concrete spalling. This is clear when comparing the test results 455 for mixes 341 and 342, as well as those for mixes 241, 242, and 243. Obviously, the inclusion 456 of high doses of PP fibres has an undesirable effect on the self-compacting and workability properties of fresh concrete; hence future work with H-TRIS will focus on defining optimum 
PP fibre doses to meet competing goals of spalling mitigation and practical workability of concrete mixes for use in various types of structural applications.

460 It should be noted that test results for mixes 132 and 142 (6 mm long monofilament PP

461 fibres) suggested that including a dose of $0.68 \mathrm{~kg}$ per $\mathrm{m}^{3}$ of $18 \mu \mathrm{m}$ diameter PP fibres was as 462 effective as including $1.20 \mathrm{~kg}$ per $\mathrm{m}^{3}$ of $32 \mu \mathrm{m}$ diameter fibres; similar slump flow was 463 measured for these mixes (refer to Table 1), hence it is not necessarily the dose of PP fibres alone that defines their effectiveness in spalling mitigation.

\subsubsection{Total PP fibre surface area}

466 Khoury [26] proposed the hypothesis that the existence of discontinuous reservoirs (at ambient and at high temperatures) is further promoted by the inclusion of PP fibres. This hypothesis suggests that at ambient temperature the presence of PP fibres promotes the creation of discrete reservoirs (i.e. air entrainment) in the concrete pore structure, whereas at elevated temperatures PP fibres create discontinuous reservoirs by micro-cracking the surrounding concrete matrix when undergoing volumetric and phase changes during heating. This potentially explains the positive influence of PP fibres in altering the moisture migration and/or evaporation within heated concrete, thus possibly accounting for their observed effects in reducing the propensity for heat-induced concrete spalling. Based on this hypothesis; the total surface area of PP fibres could potentially be a key parameter to explain the positive influence of PP fibres. Mixes 132, 142, 345, and 344 had equivalent total surface areas of PP

477 fibres; this being $165 \mathrm{~m}^{2}$ of PP fibre surface area per $\mathrm{m}^{3}$ of concrete in all cases (refer to Table 1). Although mix 341 had $165 \mathrm{~m}^{2}$ of PP fibre surface area per $\mathrm{m}^{3}$ of concrete, a high propensity for spalling was observed due to the negative effect of relatively short $(3 \mathrm{~mm})$ of the PP fibres included in this mix (as noted in the parametric analysis above). 
482 Khoury [26] also hypothesized that changes in the pore structure of concrete, and therefore reductions in the propensity for heat-induced concrete spalling, are driven by the creation of continuous channels in the cement matrix. Based on this hypothesis, the total length of PP fibres could also potentially be a key parameter to explain the positive influence of PP fibres in mitigating the propensity for spalling. Mixes 142, 345, and 344 had an equivalent total length of PP fibres; this being $1640 \mathrm{~km}$ of PP fibres per $\mathrm{m}^{3}$ of concrete (refer to Table 1). Yet again, while mix 341 had $1640 \mathrm{~km}$ of PP fibres per $\mathrm{m}^{3}$ of concrete, a high propensity for spalling was observed due to the negative effect of the relatively short $(3 \mathrm{~mm})$ PP fibres included in this mix. Thus total PP fibre length also appears not to be a fundamental parameter.

\subsubsection{Total number of individual PP fibres}

493 It is widely stated in the literature that a higher number of individual PP fibres (as well as a

494 higher dose of PP fibres) enhances the effectiveness in reducing the propensity for heat495 induced concrete spalling [31]. Nonetheless, spalling occurred for all specimens cast with 496 Mix 341 (32 $\mu$ m diameter, 3 mm long multifilament PP fibres with) which had a relatively 497 high number of individual PP fibres (547 million individual PP fibres per $\mathrm{m}^{3}$ of concrete). 498 This suggests the relevant influence of individual fibre length on the effectiveness of PP 499 fibres in reducing the propensity for heat-induced concrete spalling that warrants further 500 investigation.

501 To summarise, mixes with an equal or higher value of total surface area or total length of PP

502 fibres to those of the predefined values compared in this study $\left(165 \mathrm{~m}^{2}\right.$ or $1640 \mathrm{~km}$ of PP 503 fibres per $\mathrm{m}^{3}$ of concrete) did not spall (refer to Table 1). Furthermore, test specimens cast 504 with mixes 241 and 242, both of which had significantly lower values of all of the like-to-like 
parameters examined in the current section, spalled during testing. No spalling was observed for Mix 243, although it also had low values of total length of PP fibres and total numbers of

507 PP fibres, however with a high total surface area of PP fibres $\left(165 \mathrm{~m}^{2}\right.$ of PP fibres per $\mathrm{m}^{3}$ of 508 concrete). This suggests a possible relevance of total surface area of PP fibres as compared to 509 the total length or number of individual PP fibres.

\section{$510 \quad 5.4 \quad$ Experimental validation of the thermal exposure}

511 Three additional medium-scale concrete specimens were cast with concrete Mix 042 (refer to

512 tables 1 and 2) and instrumented with in-depth thermocouples (K-type) placed at equivalent

513 depths to those placed in the aforementioned large-scale furnace test specimens which have 514 been described elsewhere [32]; namely at 10, 20 and $45 \mathrm{~mm}$ from the exposed concrete

515 surface. These specimens were tested with H-TRIS, and in-depth temperature distribution 516 measurements were used to verify that the thermal boundary conditions imposed with H-

517 TRIS were indeed equivalent to those experienced by otherwise identical specimens during 518 standard fire resistance tests.

519 Figure 4 gives a comparison of in-depth temperature measurements between effectively identical concrete elements (identical in the direction of the principal heat flow) during fire resistance tests (shaded areas) and tested with H-TRIS (black lines), and shows very good agreement. This comparison verifies the use of H-TRIS, particularly for replicating the indepth temperature distribution experienced by concrete specimens during the fire resistance tests performed by Terrasi et al. [32]. Figure 4 also illustrates the excellent repeatability of testing with H-TRIS (three repeat tests are shown with two temperature measurements at each depth) as compared with the greater variability observed in fire resistance tests described in this paper (three repeat tests are shown with one temperature measurement at each depth). 


\section{CONCLUSIONS}

530 The studies described herein represent the first experiments ever performed using the novel

531 H-TRIS testing methodology and apparatus to simulate the net heat flux at the exposed

532 surface, and hence the in-depth time dependent temperature distributions within concrete

533 specimens, during an otherwise identical standard fire resistance test. The study aimed at

534 examining the propensity for heat-induced concrete spalling of 11 HPSCC mixes in which

535 the PP fibre type, cross-section, length, supplier, and dose were systematically varied.

536 The inclusion of PP fibres has a clear positive effect on reducing the propensity for heatinduced concrete spalling. Additionally, based on the parametric analysis and discussion presented herein, the following overall conclusions can be made on the various factors that may have an impact on PP fibre effectiveness at spalling mitigation of the HPSCC mixes

540 examined within the scope of this study:

- $\quad$ PP fibre cross-section - inclusion of PP fibres with smaller cross-sections has a positive

542 influence in reducing the propensity for spalling.

- $\quad$ PP fibre length - mixes cast with relatively short (3 mm long) PP fibres exhibit a higher

544 propensity for spalling than practically identical mixes (equivalent PP fibre dose) with

545 longer fibres (6 or $12 \mathrm{~mm}$ long); thus, longer PP fibres appear to be more effective at

$546 \quad$ reducing the propensity for spalling.

547 - PP fibre supplier - the comparison made between PP fibres manufactured by Bekaert, 548 Propex, and Vulkan showed that fibre supplier has no obvious influence on spalling (all $549 \quad$ other factors being equal).

- $\quad$ PP fibre type - monofilament or multifilament PP fibres type showed a lower propensity for heat-induced concrete spalling relative to those cast with fibrillated PP fibres. This 
may be associated with the lower specific surface area of larger cross-section fibrillated PP fibres.

- $\quad$ Sustained compressive stress - specimens for which spalling occurred under sustained compressive stress also suffered from spalling when tested under a free-to-expand conditions (with exception of Mix 242, which confirmed an influence of pre-compressive stress for this particular mix).

558 Based on the like-to-like comparisons presented, the following conclusions can be made:

- Dose of PP fibres - as expected, high doses of PP fibres have a positive influence in

560 mitigating the occurrence of spalling; however some very low doses, e.g. Mix 132 (0.68

$561 \quad \mathrm{~kg}$ of PP fibres per $\mathrm{m}^{3}$ of concrete), of specific PP fibres (e.g. those of relatively small 562 cross-section) were also effective at reducing the propensity for spalling, and some 563 comparatively high doses, e.g. Mix 242 (2.00 $\mathrm{kg}$ of PP fibres per $\mathrm{m}^{3}$ of concrete), were 564 not. This suggests that current guidance for mitigation of spalling in HPC [29] is hard to 565 defend scientifically and requires revision.

- $\quad$ Total PP fibre surface area, total PP fibre length, and total number of individual PP 567 fibres - results showed that concrete mixes with relatively high values of total PP fibres surface area, total PP fibre length, and total number of individual PP fibres were effective in reducing the propensity for heat-induced concrete spalling. However, the mix that included $3 \mathrm{~mm}$ long monofilament PP fibres had high values of all of these parameters; yet displayed a high propensity for spalling. Moreover, no spalling was observed for Mix 243 which included $20 \mathrm{~mm}$ long fibrillated PP fibres at a comparatively high dose of $2.34 \mathrm{~kg}$ of PP fibres per $\mathrm{m}^{3}$ of concrete. Although this mix had low values of total PP fibre length and the total number of PP fibres, it had a similar total surface area of PP 
fibres to other mixes ( $165 \mathrm{~m}^{2}$ of PP fibres per $\mathrm{m}^{3}$ of concrete). This suggests a relevance of the total surface area of PP fibres over the total PP fibre length or total number of PP fibres, while assuming that the shape of the cross section (rectangular or circular) is negligible.

579 The inclusion of PP fibres has an obvious negative effect on slump flow values.

580 Polypropylene fibres with reduced cross-section and/or large individual lengths showed a more negative influence on slump flow, compared to PP fibres with increase cross-section and short individual lengths. Inclusion of PP fibres showed no obvious influence on moisture content or compressive strength.

584 Based on the use of H-TRIS within the scope of the work carried for the study described

585 herein, the following observations may be made in regards to the novel test method:

586 - Test results verified the use of H-TRIS, particularly for simulating specified in-depth 587 temperature distributions and time-to-spalling experienced by concrete specimens during 588 the large-scale furnace test presented by Terrasi et al. [32]; providing excellent 589 repeatability at a low economic and temporal cost and with outstanding repeatability.

- The use of H-TRIS allowed accurate quantification of the time to first spalling, the mass 591 spalled, and the net heat density of the tested specimens. Spalling occurred between 7 592 and 25 minutes from the start of the test. When spalling occurred, the mass spalled from 593 tested specimens was between 0.9 and $28.5 \%$ of the total weight of the specimen before 594 testing; in most cases the test results indicate that when spalling occurs at an early stage 595 of the test the mass spalled is lower than when it occurs at a later stage. 


\section{ACKNOWLEDGEMENTS}

598 The authors would like to thank SACAC Schleuderbetonwerk AG and The University of 599 Edinburgh, and in particular Lukas Bäurle, Nunzio Spano, Birol Kanik, and Etienne

600 Dessendier. This research was partially funded by the BRE Centre for Fire Safety 601 Engineering at The University of Edinburgh and Empa. Arup and the Royal Academy of 602 Engineering are gratefully acknowledged for their ongoing support of Arup Prof Bisby.

\section{REFERENCES}

604 [1] Bilow D.N. and Kamara M.E. Fire and Concrete Structures. Proceedings of the ASCE 605 Structures Congress 2008: Crossing Borders, Vancouver, Canada, 2008, 10 pp.

606 [2] Mehta P.K. and Aïtcin P.C. Principles Underlying Production of High-Performance 607 Concrete. ASTM - Cement, Concrete, and Aggregates, 1990, 12 (2), 70-78.

608 [3] Walraven J. High-Strength Concrete in the Netherlands. American Concrete Institute 609 Special Publication on High Strength Concrete: An International (ACI SP-167-5), $610 \quad 1997,103-126$.

611 [4] Bentz D.P. Fibers, Percolation, and Spalling of High Performance Concrete. ACI 612 Materials Journal, 2000, 97 (3), 351-359.

613 [5] Kodur V.K.R. and Phan L. Critical Factors Governing the Fire Performance of High 614 Strength Concrete Systems. Fire Safety Journal, 2007, 42 (6-7), 482-488.

615 [6] Mehta P.K. Advancements in Concrete Technology. Concrete International, 1999, 21 $616 \quad(6), 69-76$. 
617 [7] Maluk C. Development and Application of a Novel Test Method for Studying the Fire 618 Behaviour of CFRP Prestressed Concrete Structural Elements. PhD Thesis, The 619 University of Edinburgh, UK, 2014, 473 pp.

620 [8] Boström L. and Jansson R. Fire Resistance. RILEM TC 205-DSC: State-of-the-Art 621 Report, 2007, 143-152.

622 [9] Miller R.P. Legislation Concerning the Use of Cement in New York City. Proceedings 623 of the National Association of Cement Users, 1906, 186-197.

624 [10] Hull W.A. and Ingberg S.H. Fire Resistance of Concrete Columns. Technologic Papers 625 of The Bureau of Standards (No.272), 1925, 635-708.

[11] Meyer-Ottens C. Abplatzungsversuche (Spalling Tests). Technical University of 627 Braunshweig (internal report), Braunshweig, Germany, 1965, 59-66.

[12] Dougill J.W. The Effects of High Temperature on the Strength of Concrete with Reference to Thermal Spalling. PhD Thesis, King's College London, UK, 1971, 502 pp.

[13] Chandra S., Berntsson L., and Andergerg Y. Some Effects of Polymer Addition on the 631 Fire Resistance of Concrete. Cement and Concrete Research, 1980, 10 (3), 367-375.

632 [14] Copier W.J. The Spalling of Normal Weight and Lightweight Concrete on Exposure to Fire. American Concrete Institute Special Publication on High Strength Concrete: An International (ACI SP-80-7), 1983, 219-236.

[15] Chan S.Y.N., Peng G.F., and Anson M. Fire Behavior of High-Performance Concrete 636 Made with Silica Fume at Various Moisture Contents. ACI Materials Journal, 1999, 96

637 (3), 405-409. 
[16] Bailey C.G. Holistic Behaviour of Concrete Buildings in Fire. Proceedings of the Institution of Civil Engineering - Structures and Buildings, 2002, 152 (3), 199-212.

[17] Hertz K.D. and Sørensen L.S. Test Method for Spalling of Fire Exposed Concrete. Fire Safety Journal, 2005, 40 (5), 466-476.

[18] Jansson R. and Boström L. The Influence of Pressure in the Pore System on Fire Spalling of Concrete. Fire Technology, 2010, 46 (1), 271-230.

[19] Connolly R.J. The Spalling of Concrete in Fires. PhD Thesis, Aston University, UK, $1995,295 \mathrm{pp}$

[20] Ahmed G.N. and Hurst J.P. Modelling Pore Pressure, Moisture, and Temperature in High-Strength Concrete Columns Exposed to Fire. Fire Technology, 1999, 35 (3), 232262.

[21] Shamalta M., Breunese A., Peelen W., and Fellinger J. Numerical Modelling and Experimental Assessment of Concrete Spalling in Fire. Heron Journal, 2005, 50 (4), 303-319.

[22] Arup Fire. Fire Resistance of Concrete Enclosure - Work Package 3 and 4 (Rev A). Elaborated for the Nuclear Safety Directorate of the Health and Safety Executive, London, UK, 2005, 52 pp.

[23] Deeny S., Stratford T., Dhakal R.P., Moss P.J., and Buchanan A.H. Spalling of Concrete: Implications for Structural Performance in Fire. Proceedings of the International Conference Applications of Structural Fire Engineering, Prague, Czech Republic, 2008, 202-207. 
659 [24] Bilodeau A., Kodur V.K.R., and Hoff G.C. Optimization of the Type and Amount of 660 Polypropylene Fibres for Preventing the Spalling of Lightweight Concrete Subjected to 661 Hydrocarbon Fire. Cement \& Concrete Composites, 2004, 26 (2), 163-174.

662 [25] Jansson R. Fire Spalling of Concrete - Theoretical and Experimental Studies. PhD 663 Thesis, KTH Royal Institute of Technology, Stockholm, Sweden, 2013, 154 pp.

664 [26] Khoury G.A. Polypropylene Fibres in Heated Concrete - Part 2: Pressure Relief 665 Mechanisms and Modelling Criteria. Magazine of Concrete Research, 2008, 60 (3), 666 189-204.

667

[27] Kumar R., Goel P., and Mathur R. Suitability of Concrete Reinforced with Synthetic 668 Fiber for the Construction of Pavements. Proceedings of the $3^{\text {rd }}$ International 669 Conference on Sustainable Construction Materials and Technologies, Kyoto, Japan, 670 2013, 8 pp.

671 [28] Heo Y.S., Sanjayan J.G., Han C.G., and Han M.C. Critical Parameters of Nylon and 672 other Fibres for Spalling Protection of High Strength Concrete in Fire. Materials and Structures, 2011, 44 (3), 599-610.

[29] Eurocode: Design of Concrete Structures - Parts 1-2: General rules - Structural Fire 675 Design (EN 1992-1-2). European Committee for Standardization, Brussels, Belgium, 2004, $100 \mathrm{pp}$.

677 [30] CCAA. Fire Safety of Concrete Buildings. Cement Concrete \& Aggregates Australia 678 (CCAA), 2013, 33 pp. 
679 [31] Heo Y.S., Sanjayan J.G., Han C.G., and Han M.C. Relationship between inter680 aggregate spacing and the optimum fiber length for spalling protection of concrete in fire. Cement and Concrete Research, 2012, 43 (3) 549-557.

682

683

684

685

686

687

688

689

690

691

692

693

694

695

696

697

698

699

[32] Terrasi G.P., Bisby L., Barbezat M., Affolter C., and Hugi, E. Fire Behavior of Thin CFRP Pretensioned High-Strength Concrete Slabs. Journal of Composites for Construction, 2012, 16 (4), 381-394.

[33] Maluk C., Bisby L., Krajcovic M., and Torero J.L. The Heat-Transfer Rate Inducing System (H-TRIS) Test Method. Fire Safety Journal, 2015. (sent to editor)

[34] Robertson A.F. Development of an improved radiant heat source for fire testing, Fire and Materials, 1982, 6 (2), 68-71.

[35] Eurocode: Design of Concrete Structures - Parts 1-1: General Rules and Rules for Buildings (EN 1992-1-1:2004). European Committee for Standardization, Brussels, Belgium, 2004, 230 pp.

[36] Eurocode: Testing Fresh Concrete - Part 8: Self-compacting Concrete - Slump-Flow Test (EN 12350-8:2010). European Committee for Standardization, Brussels, Belgium, 2010, 14 pp.

[37] Zeiml M., Lackner R., and Mang H.A. Experimental Insight into Spalling Behavior of Concrete Tunnel Linings Under Fire Loading. Acta Geotechnica, 2008, 3 (4), 295-308.

[38] Maluk C., Bisby L., and Terrasi G.P. Effects of polypropylene fibre type on occurence of heat-induced concrete spalling. Proceedings of the $3^{\text {rd }}$ International RILEM Workshop on Concrete Spalling due to Fire Exposure, Paris, France, 2013, 51-58. 